\title{
Study on adsorptive capability of acid activated charcoal for desulphurization of model and commercial fuel oil samples
}

\author{
Syed Sikandar Shah ${ }^{\mathrm{a}, \mathrm{b}, *}$, Imtiaz Ahmad ${ }^{\mathrm{b}}$, Waqas Ahmad $^{\mathrm{b}}$, Muhammad Ishaq ${ }^{\mathrm{b}}$, Kashif Gul ${ }^{\mathrm{b}}$, \\ Razia Khan ${ }^{\mathrm{b}}$, Hizbullah Khan ${ }^{\mathrm{c}}$

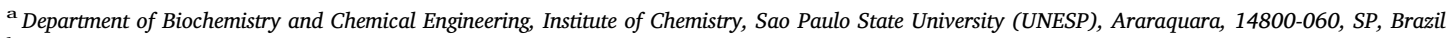 \\ ${ }^{\mathrm{b}}$ Institute of Chemical Sciences, University of Peshawar, 25120, KPK, Pakistan \\ ${ }^{\mathrm{c}}$ Department of Environmental Sciences, University of Peshawar, 25120, KPK, Pakistan
}

\section{A R T I C L E IN F O}

\section{Keywords:}

Petroleum

Model oil

Desulphurization

Environment

Regeneration

\begin{abstract}
A B S T R A C T
The present study was planned to explore the selective desulphurization efficiency of the acid-modified activated charcoal (AC) as an adsorbent. The oil samples selected were the model oil and the commercial kerosene \& diesel. The adsorption capacity of the AC was evaluated for the removal of one of the sulfur analogs i.e. dibenzothiophene (DBT) present in the fuel samples under a set of experimental conditions. The kinetics and thermodynamics of the DBT desulphurization were studied. It was observed that the adsorption firmly followed pseudo-second order kinetic model. Moreover, the experimental value of the amount of DBT adsorbed at equilibrium " $q_{\mathrm{e}}$ " was nearly equal to the value calculated from the pseudo-second order kinetic model. Langmuir and Freundlich adsorption isotherm models were applied and the experimental data best fitted with the Langmuir and Freundlich adsorption isotherm models. Compared to other commercially available adsorbents, the acid-modified AC was found to be cost-effective, highly efficient and selective for the DBT removal from the model as well as real petroleum based oils.
\end{abstract}

\section{Introduction}

In petroleum based oils, the compounds of sulfur are considered undesirable due to several obnoxious effects on refinery equipment and ambient air quality [1]. During combustion, the production of the oxides of sulfur is considered a major threat to environmental degradation. In order to curb the issue, some rigorous regulations recently announced by Euro V norms, the sulfur contents in the marketable products at the refinery has to be reduced as low as 10 ppmw [1-3]. In 2007, Japan also suggested sulfur level of $10 \mathrm{ppm}$ in the transportation fuel [4]. As required by the regulations, the refiners must have strict compliance and should adopt strategies to keep the levels of sulfur in marketable products below the threshold limit. Several methods of desulphurization have been studied and reported in the open literature [5-7]. Intensive studies have been carried out on the catalytic and noncatalytic desulphurization of fuel samples $[8,9]$. Among all these methods, adsorption using carbon-based adsorbents seems to be the more realistic one than the other methods owing to several advantages including its low cost and operational safety reasons [10,11]. Activated carbons (ACs) are being extensively used as adsorbents for the removal of micro-pollutants from wastewater [12], heavy metals [13] and deep desulphurization of fuel oil samples with greater success owing to their excellent properties [14-16].

In the present study, activated charcoal was modified with hydrochloric acid in order to increase its porosity by opening the blind pores and to enhance the number of surface oxygen functional groups that can act as active sites for the selective adsorption of aromatic sulfur species from the model and real commercial kerosene and diesel oil samples. Several adsorption parameters were studied to get optimum desulphurization of DBT from the simulated oil. The optimized reaction conditions were further applied to the real oil samples.

\section{Materials and methods}

\subsection{Activated charcoal (AC)}

AC (granular) was purchased from Sigma Aldrich. It was pulverized $(100 \%<180 \mu \mathrm{m})$ using a mechanical crusher. The finely sized AC was stored in an airtight vial for use in subsequent desulphurization studies.

\footnotetext{
* Corresponding author at: Department of Biochemistry and Chemical Engineering, Institute of Chemistry, Sao Paulo State University (UNESP), Araraquara, 14800-060, SP, Brazil.

E-mail address: syed@iq.unesp.br (S.S. Shah).
} 


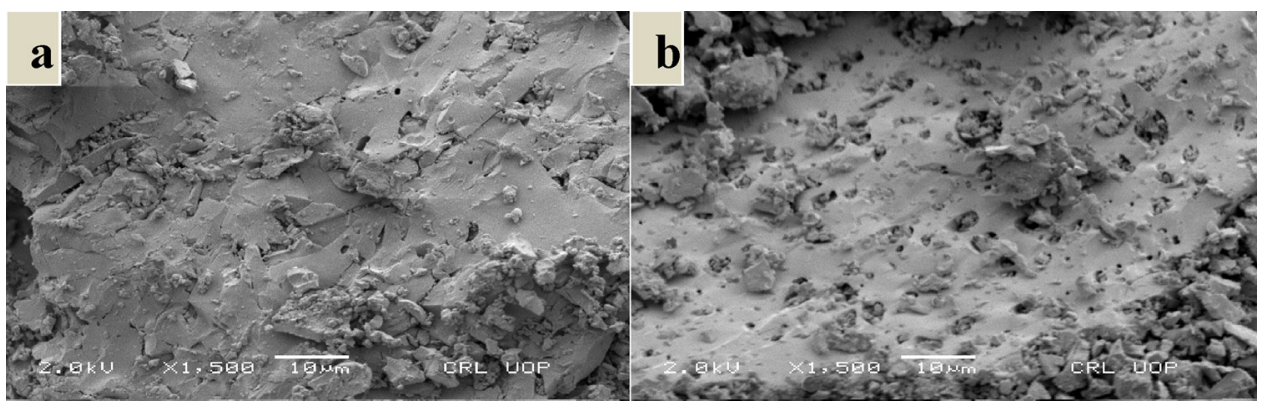

Fig. 1. SEM micrographs of the adsorbents (a) plain AC (b) acid modified AC.

\subsection{Acid modification of $A C$}

The powdered AC was first washed several times with hot distilled water (DW) to remove foreign impurities and then added to a beaker containing concentrated hydrochloric acid (37\%). For each gram of AC, about $5 \mathrm{~mL}$ of the acid was used. The contents were stirred for time duration of $3 \mathrm{~h}$ at $50{ }^{\circ} \mathrm{C}$ using a magnetic stirrer cum heater, filtered and washed thoroughly with copious amount of DW until free of acids. The residual AC was dried in an oven at $105^{\circ} \mathrm{C}$ overnight and stored in an airtight glass vial for the subsequent adsorption studies.

\subsection{Model oil (MO) preparation}

Analytical grade dibenzothiophene (DBT) $\left(\mathrm{C}_{12} \mathrm{H}_{8} \mathrm{~S}, 184.3 \mathrm{~g} \mathrm{~mol}^{-1}\right)$ and cyclohexane (99\%) were purchased from Sigma Aldrich and used without further purification. An aliquot of $1 \mathrm{~g}$ of DBT was dissolved in a little cyclohexane, the contents were shaken rigorously and made with more cyclohexane up to $1 \mathrm{~L}$. The resultant solution was of $1000 \mathrm{ppm}$ concentration from which standard DBT solutions were prepared and their concentrations were confirmed by UV-vis double beam spectrophotometer [17].

\subsection{Desulphurization of model and real oil samples}

In a typical desulphurization experiment, a known amount of the adsorbent was added to a quick fit conical flask fitted with a reflux condenser, to which $15 \mathrm{~mL}$ aliquot of the oil sample under study was added. The mixture was heated at $60^{\circ} \mathrm{C}$ with constant stirring for 60 min contact time. The contents were then filtered using Whatman filter paper no. 42 . The filtrates were collected and the residual DBT concentration was analyzed spectrophotometrically using standard calibration curve method.

Batch adsorption studies were performed in the same fashion in order to study the effect of different adsorption parameters as; stirring speed, adsorbent dosage, reaction temperature, and contact time.

Desulphurization experiments of the real commercial oil samples were carried out in the same fashion under the optimized experimental conditions.

\subsection{Regeneration of the spent adsorbent}

The spent adsorbent regeneration studies were carried out by filtering the adsorbent saturated with DBT from the model oil at the optimized conditions. The DBT desorption was performed by washing the spent adsorbents with methanol, acetonitrile, chloroform, and toluene separately $[18,19]$. For each gram of the spent saturated adsorbent, about $5 \mathrm{~mL}$ of the tested solvent was used and were shaken for $10 \mathrm{~min}$ at ambient temperature $\left(30^{\circ} \mathrm{C}\right)$. The regenerated adsorbent was filtered and dried in an oven which was reused for the next adsorption cycle.

\subsection{Analysis and characterization of adsorbent and oil samples}

\subsubsection{Adsorbent characterization}

2.6.1.1. Textural and surface properties. The texture and morphology of the $\mathrm{HCl}$ modified AC were examined by scanning electron microscope (SEM) Model No. JEOL-Jsm-5910; Japan. The surface properties were determined by surface area and pore size analyzer (NOVA 1200e).

\subsubsection{Analysis of oil samples}

2.6.2.1. Physico-chemical properties. Kerosene and diesel oil samples were characterized by using ASTM/IP standard methods. The total organic sulfur contents of the real oil samples were found to be $1.352 \mathrm{wt}$ $\%$ for kerosene and $1.871 \mathrm{wt} \%$ for diesel oil respectively $[17,19]$.

2.6.2.2. Spectroscopic analysis. The model oil, as well as kerosene and diesel oil samples were analyzed using a double beam UV-vis spectrophotometer [Shimadzu 160 A, Japan] for sulfur contents. The spectrum was recorded against cyclohexane as reference solvent at $200-400 \mathrm{~nm}$. From the stock solution of model oil (1000 ppm DBT prepared in cyclohexane), a series of working solutions were prepared by dilution in cyclohexane. The absorbance of each of the working solutions was recorded at $320 \mathrm{~nm}$. A calibration curve was constructed, and the straight line equation was used to calculate the DBT concentration in the oil samples before and after adsorption [17].

\section{Results}

The treatment of the AC with $\mathrm{HCl}$ was done with the objectives to enhance its surface and adsorptive properties. The plain and the acidmodified AC samples were analyzed by SEM and surface area analyzer. The corresponding SEM micrographs are provided in Fig. 1(a,b). It is clear from the micrographs that the micro and mesoporosity is enhanced to a great extent with the $\mathrm{HCl}$ treatment compared with the plain AC. The BET surface area $\left(\mathrm{S}_{\mathrm{BET}}\right)$, BJH surface area $\left(\mathrm{S}_{\mathrm{BJH}}\right)$, average pore size and average pore volume of the plain and modified adsorbent were determined using nitrogen isotherms at $77.4 \mathrm{~K}$. The results are compiled in Table 1. Physico-chemical properties were determined in case of the real oil samples. The effect of the adsorbent dosage (m) on the DBT adsorption was studied. The results are provided in Fig. 2. The rate of adsorption was studied using various adsorbent doses selected in the range of $0.2-1.5 \mathrm{~g} / 15 \mathrm{~mL}$. All other experimental conditions such as temperature $\left(60^{\circ} \mathrm{C}\right)$, stirring speed $(100 \mathrm{rpm})$, contact time $(60 \mathrm{~min})$ and initial DBT concentration (1000 ppm) were kept constant.

The adsorption experiments were performed at four different

Table 1

Surface properties of the plain and acid modified AC.

\begin{tabular}{lllll}
\hline Adsorbent & $\begin{array}{l}\text { BET Surface } \\
\text { area }\left(\mathrm{m}^{2} \mathrm{~g}^{-1}\right)\end{array}$ & $\begin{array}{l}\text { BJH Surface } \\
\text { area }\left(\mathrm{m}^{2} \mathrm{~g}^{-1}\right)\end{array}$ & $\begin{array}{l}\text { Pore diameter } \\
(\mathrm{A})\end{array}$ & $\begin{array}{l}\text { Pore volume } \\
\left(\mathrm{cm}^{3} \mathrm{~g}^{-1}\right)\end{array}$ \\
\hline Plain AC & 800.41 & 50.41 & 23.25 & 0.05 \\
HCl-AC & 1030.79 & 137.33 & 120.43 & 0.60 \\
\hline
\end{tabular}




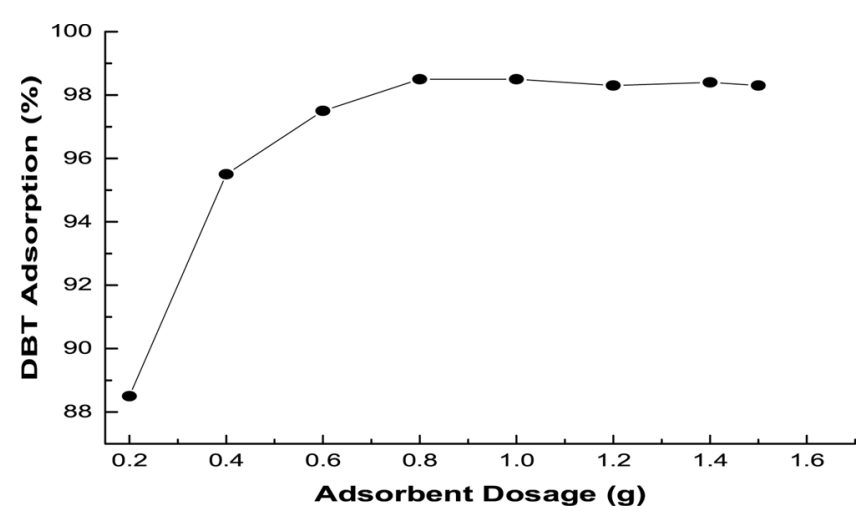

Fig. 2. DBT adsorption as a function of $\mathrm{HCl}-\mathrm{AC}$ adsorbent dosage.

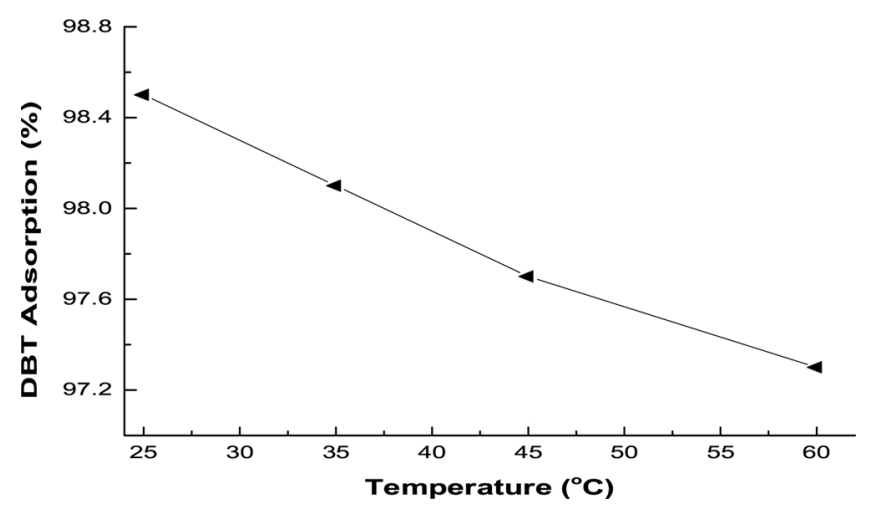

Fig. 3. DBT adsorption as a function of temperature.

temperature conditions $\left(25,35,45\right.$ and $\left.60^{\circ} \mathrm{C}\right)$ in order to study the effect of adsorption temperature. The results are provided in Fig. 3 . The other experimental conditions of stirring speed $(100 \mathrm{rpm})$, adsorbent dosage $(0.8 \mathrm{~g})$ and initial DBT concentration $(1000 \mathrm{ppm})$ were kept constant.

The adsorption kinetics was studied at four different contact times $(15,30,45$ and $60 \mathrm{~min})$ for the determination of kinetic parameters. The amount of adsorbent dosage $(0.8 \mathrm{~g})$ and the reaction temperature of $60^{\circ} \mathrm{C}$ were applied as optimum reaction conditions. Other reaction conditions such as stirring speed (100 rpm), initial DBT concentration $(1000 \mathrm{ppm})$ and at neutral $\mathrm{pH}$ were kept constant. The results are compiled in Fig. 4.

The prediction of the adsorption kinetics is necessary for the design of industrial adsorption columns. In the present study, frequently used kinetic models, namely Pseudo-first-order and Pseudo-first order equations were applied. Pseudo-second order model best fits with the current data, assuming non-dissociating molecular adsorption of DBT onto HCl-AC. The values calculated from the experimental data are provided in Table 2 .
Table 2

Kinetic Parameters of DBT Adsorption over HCl-AC.

\begin{tabular}{|c|c|c|c|}
\hline \multicolumn{2}{|c|}{$\begin{array}{l}\text { Pseudo-first order equation } \\
\text { parameters }\end{array}$} & \multicolumn{2}{|c|}{ Pseudo-second order equation parameters } \\
\hline $\mathrm{K}_{1}\left(\min ^{-1}\right)$ & 0.0391 & $\mathrm{~K}_{2}\left(\mathrm{mg} \mathrm{g}^{-1} \min ^{-1}\right)$ & 0.266 \\
\hline $\mathrm{q}_{\mathrm{e}}\left(\mathrm{mg} \mathrm{g}^{-1}\right)$ & 2.254 & $\mathrm{q}_{\mathrm{e}}\left(\mathrm{mg} \mathrm{g}^{-1}\right)$ & 25 \\
\hline $\mathrm{R}^{2}$ & 0.992 & $\mathrm{R}^{2}$ & 1 \\
\hline
\end{tabular}

Two adsorption isotherm models were applied namely Langmuir and Freundlich isotherm model. The Langmuir model is developed to represent chemisorption on a set of well-defined localized adsorption sites having the same sorption energies independent of surface coverage and no interaction between adsorbed molecules.

$\frac{C_{e}}{X_{e}}=\frac{1}{K_{l} q_{m}}+\frac{1}{q_{m}} C_{e}$

Wherein " $\mathrm{X}_{\mathrm{e}}$ " is the DBT adsorption amount at equilibrium (mg/g), " $\mathrm{C}_{\mathrm{e}}$ " is the equilibrium DBT concentration in solution $(\mathrm{mg} / \mathrm{L})$, " $q_{\mathrm{m}}$ " is the maximum adsorption capacity $(\mathrm{mg} / \mathrm{g})$, and " $\mathrm{K}_{1}$ " is the Langmuir adsorption equilibrium constant. As shown in Fig. 5, the plot of " $C_{\mathrm{e}} / X_{e}$ " versus " $C_{\mathrm{e}}$ " yielded a straight line.

The Freundlich adsorption isotherm gives an expression encompassing the surface heterogeneity and the exponential distribution of the active sites and their energies [20]. The Freundlich isotherm model can be shown in the given relation:

$\ln X_{e}=\ln K_{f}+1 / n \ln C_{e}$

Where " $\mathrm{K}_{\mathrm{f}}$ " is the Freundlich constant, and " $\mathrm{n}$ " is the adsorption intensity.

Several adsorption parameters were optimized using simulated oil and the same set of optimized conditions was applied for the deep desulphurization of the real commercial fuel samples.

\section{Discussion}

\subsection{Characterization of adsorbent}

The SEM morphological study of the adsorbent indicates that the micro and mesoporosity in case of the plain AC (Fig. 1(a)) was boosted significantly with the acid treatment (Fig. 1(b)).

The results of surface properties i.e. BET surface area $\left(\mathrm{S}_{\mathrm{BET}}\right), \mathrm{BJH}$ surface area $\left(\mathrm{S}_{\mathrm{BJH}}\right)$, average pore size and average pore volume (Table 1 ) indicate that the BET surface area $\left(\mathrm{S}_{\mathrm{BET}}\right)$ calculated in case of the plain $\mathrm{AC}$ was found to be $800.41 \mathrm{~m}^{2} \mathrm{~g}^{-1}$, the BJH surface area $\left(\mathrm{S}_{\mathrm{BJH}}\right)$ was $50.41 \mathrm{~m}^{2} \mathrm{~g}^{-1}$, with average pore volume of $0.05 \mathrm{~cm}^{3} \mathrm{~g}^{-1}$ and average pore diameter of $23.25 \AA$ Á.

In comparison to the plain $\mathrm{AC}$, these properties were improved in case of the acid-modified AC. The $\mathrm{S}_{\mathrm{BET}}$ was found to be $1030.79 \mathrm{~m}^{2} \mathrm{~g}^{-1}$, and the $\mathrm{S}_{\mathrm{BJH}}$ surface area was found to be $137.33 \mathrm{~m}^{2} \mathrm{~g}^{-1}$. About $22.34 \%$ increase in surface area in case of the $\mathrm{S}_{\mathrm{BET}}$ while $63.29 \%$ increase in
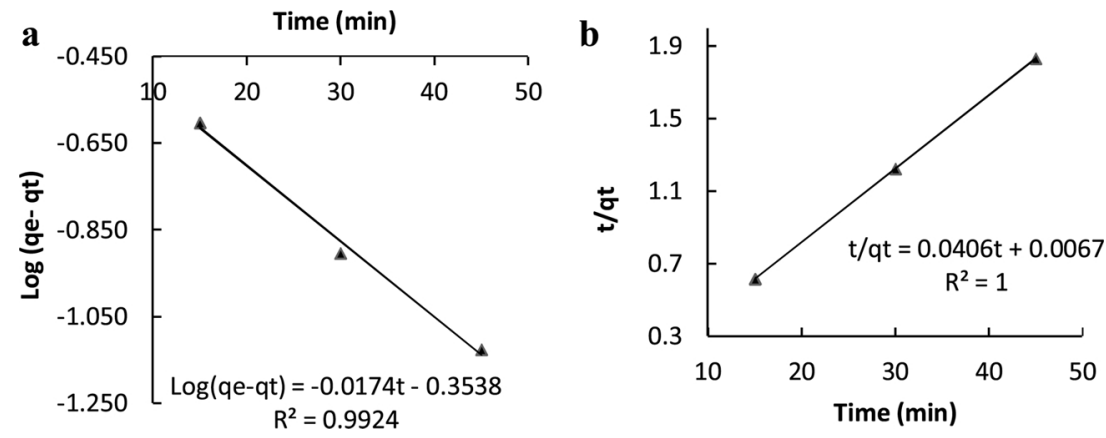

Fig. 4. Adsorption kinetics plots for the DBT adsorption by HCl-AC (a) pseudo first order and (b) pseudo-second order. 

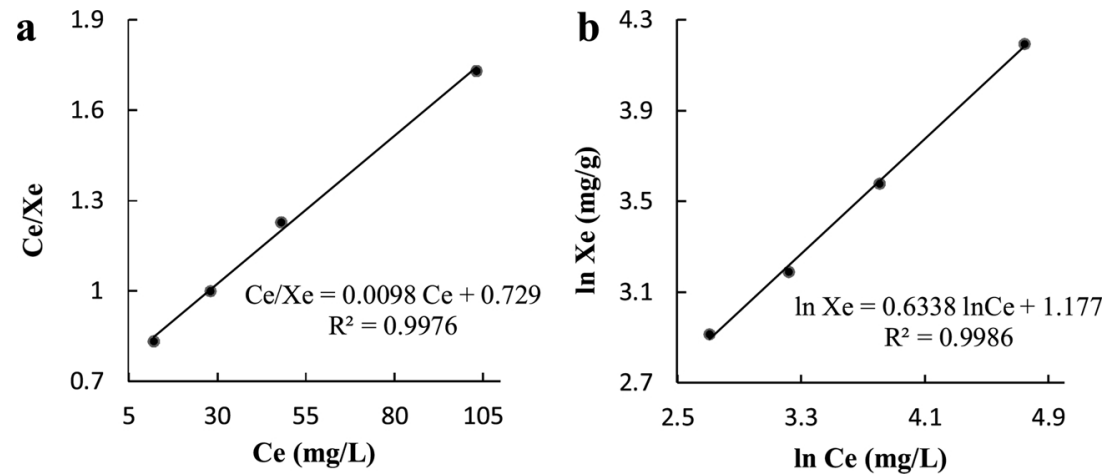

Fig. 5. Adsorption isotherms for DBT adsorption over HCl-AC (a) Langmuir and (b) Freundlich.

BJH surface area was observed. The pore volume was observed to be $0.60 \mathrm{~cm}^{3} \mathrm{~g}^{-1}$ and average pore diameter was found to be $120.43 \AA$ A. In comparison to the plain AC, a significant increase in average pore volume and average pore diameter was observed. The results indicate that acid modification caused a synergistic effect on the improvement in the textural as well the surface properties [15]. Most of the adsorbents used for the adsorptive desulphurization of aromatic sulfur compounds constitute a mesoporous structure $(2-50 \mathrm{~nm})$, which is essential in the adsorption of the sulfur species since the size of the pores should have the same magnitude for the adsorption to occur [21]. Based on the improved properties, the $\mathrm{HCl}$ modified AC was selected as an adsorbent for the deep desulphurization of the oil samples under study.

\subsection{Physico-chemical properties}

For the characterization of kerosene and diesel samples, different physicochemical properties were examined, which meet the standard commercial kerosene and diesel oil specifications [17,19,22,23]. The total organic sulfur contents of the real oil samples were found to be high $(>1 \%)$, which must be treated to retain the sulfur content below the threshold limit [19].

\subsection{Model oil desulphurization}

\subsubsection{Effect of adsorbent dosage}

The effect of the adsorbent dosage (m) on the DBT removal from model oil was studied. The results (Fig. 2) indicate that the percent DBT adsorption increased from 88.5 up to a maximum of $98.5 \%$ with the increase in adsorbent dose from 0.2 to $0.8 \mathrm{~g}$ which can be attributed to the availability of more surface area and adsorption sites [24]. At an adsorbent dose of $\mathrm{m}>0.8 \mathrm{~g}$, the adsorption seems to be the same which can be ascribed to the saturation of the adsorption sites and no further sites are available to retain DBT. Based on the results, $0.8 \mathrm{~g}$ was chosen as the optimum amount of the adsorbent.

\subsubsection{Effect of temperature}

The experiments were carried out at four different temperatures i.e. $25,35,45$ and $60^{\circ} \mathrm{C}$. The other experimental condition of stirring speed (100 rpm), adsorbent dosage $(0.8 \mathrm{~g})$ and initial DBT concentration $(1000 \mathrm{ppm})$ were kept constant. The results provided in Fig. 3 indicate that at $25^{\circ} \mathrm{C}$, the adsorption was observed to be maximum i.e. $98.5 \%$. With the increase in temperature up to $60^{\circ} \mathrm{C}$, the adsorption showed a gradual decline. The reason may be due to the elevated temperature, the rate of desorption increases due to increase in kinetic energy of the DBT molecules [25-27]. In addition, changing the reaction temperature can possibly change the DBT equilibrium capacity of the adsorbent [25]. The results suggest that the DBT adsorption over HCl-AC is exothermic in nature and maximum removal is favored at lower temperature [3].

\subsubsection{Effect of contact time}

A series of contact time experiments was carried out with adsorbent dosage $0.8 \mathrm{~g}$, initial DBT concentration of $1000 \mathrm{ppm}$, temperature $60^{\circ} \mathrm{C}$, and stirring speed of $100 \mathrm{rpm}$ at neutral $\mathrm{pH}$. The contact time necessary to reach DBT adsorption equilibrium was found to be $60 \mathrm{~min}$. The time required to attain this state of equilibrium of DBT adsorption at the equilibrium time reflects the maximum capacity of the HCl-AC under the operating conditions. On the basis of these results, contact time of $60 \mathrm{~min}$ was selected as the optimal time for the maximum adsorption of DBT from the model oil.

\subsubsection{Adsorption kinetics}

To select the optimum conditions for designing the DBT adsorption system, the kinetically data are of prime importance. For such purpose, two well-known kinetic models namely pseudo-first and pseudo-second order equations were applied to the data. The results are provided in Fig. 4. According to the pseudo-second order equation, the expected experimental value determined for the amount of DBT adsorbed at equilibrium " $\mathrm{q}_{\mathrm{e}}$ " was close to the calculated value and the regression value $\left(\mathrm{R}^{2}\right)$ was found to be 1 (Table 2). The linearization confirmed that the pseudo-second kinetic model describes fairly well the DBT adsorption mechanism. The experimental " $\mathrm{q}_{\mathrm{e}}$ " value was found to be $24.625 \mathrm{mg} \mathrm{g}^{-1}$ compared with the calculated experimental value of $25 \mathrm{mg} \mathrm{g}^{-1}$. Moreover, the DBT adsorption on $\mathrm{HCl}-\mathrm{AC}$ was also found to be faster $\left(\mathrm{K}_{2}=0.266 \mathrm{mg} \mathrm{g}^{-1}\right)$ as $\left(\mathrm{K}_{1}=0.0391 \mathrm{~min}^{-1}\right)$. This approves that the rate-limiting step is chemisorption and the pseudo-second order equation best fits the current data and has higher correlation coefficient as compared to the pseudo first order equation.

\subsubsection{Adsorption isotherms}

The Langmuir model is developed to represent chemisorptions on a set of well-defined localized adsorption sites having the same sorption energies independent of surface coverage and no interaction between adsorbed molecules.

As shown in Fig. 5(a), the plot of $\mathrm{Ce} / \mathrm{Xe}$ versus $\mathrm{Ce}$ yielded a straight line. From the slope and intercept, the values of " $\mathrm{q}_{\mathrm{m}}$ " and " $\mathrm{K}_{\mathrm{l}}$ " were estimated with the correlation coefficient.

The linear plot of "ln Xe" against "In Ce" represents the Freundlich isotherm model (Fig. 5(b)) and from the slope and intercept, the values of " $n$ " and "Kf" were calculated which are tabulated in Table 3. Larger "Kf" means higher adsorption capacity, and larger " $\mathrm{n}$ " value implies a

Table 3

DBT adsorption isotherm parameters with their corresponding correlation coefficients.

\begin{tabular}{|c|c|c|c|}
\hline \multicolumn{2}{|c|}{ Langmuir isotherm parameters } & \multicolumn{2}{|c|}{ Freundlich isotherm parameters } \\
\hline $\mathrm{q}_{\mathrm{m}}(\mathrm{mg} / \mathrm{g})$ & 102.04 & $\mathrm{n}$ & 1.577 \\
\hline $\mathrm{K}_{1}$ & 0.0134 & $\mathrm{~K}_{\mathrm{f}}$ & 0.0710 \\
\hline $\mathrm{R}^{2}$ & 0.997 & $\mathrm{R}^{2}$ & 0.998 \\
\hline
\end{tabular}




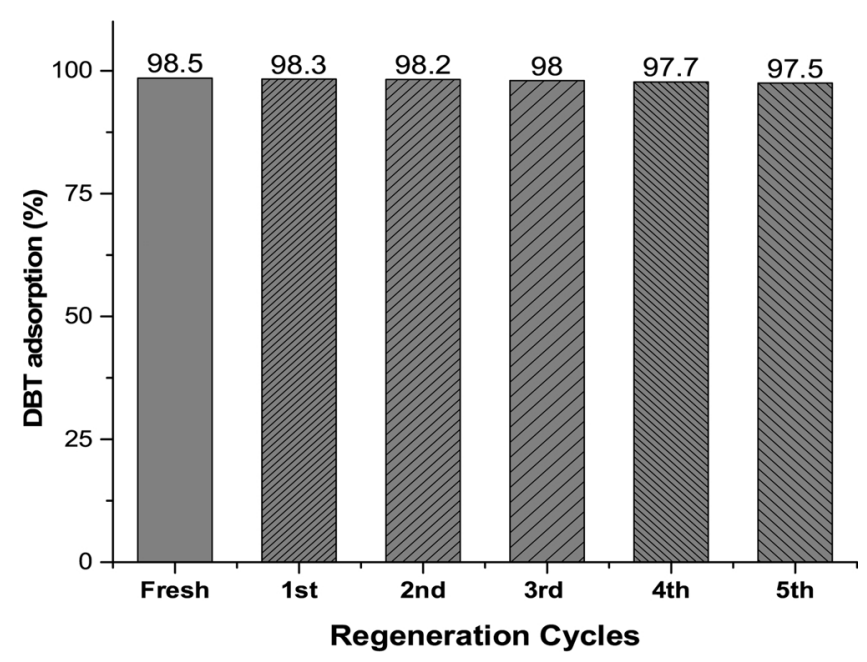

Fig. 6. Regeneration performance of $\mathrm{HCl}-\mathrm{AC}$ in terms of DBT adsorption.

more nonlinear adsorption isotherm and more heterogeneous adsorption system [28]. The results demonstrate that the experimental data fitted both the Langmuir and Freundlich adsorption isotherms.

\subsubsection{Adsorption-desorption cycles}

Among all four solvents used, toluene was selected having the greatest potential for the regeneration of the spent adsorbent and was applied in all subsequent regeneration cycles. The porosity of the spent adsorbent was enhanced to a greater extent because of the desorption of the DBT molecules from the blind pores of the spent saturated adsorbent using toluene as a washing solvent [29]. DBT showed very high solubility in toluene and the regeneration capability was much more effective as compared to other solvents tested [17,19,30]. Fig. 6 illustrates the DBT adsorption capacity due to the multifold regeneration of the spent HCl-AC.

Rui et al. [3] reported that due to the harsh thermal treatment of the spent adsorbent, the sulfur adsorption capacity was decreased with the increase in the regeneration cycle. Since in the current study, there is the almost negligible difference in the DBT adsorption capacity as there is no harsh treatment in regenerating the spent adsorbent. Thus it can be concluded that the solvent washing is an important step in the regeneration cycles and the spent adsorbent can be completely regenerated without losing its adsorption capacity for the aromatic sulfur species [31].

Fig. 7(a,b) depicts the SEM micrograph of HCl-AC before and after five successive regeneration cycles. The micrograph of spent adsorbent, treated with model oil for five successive adsorption-desorption cycles is shown in Fig. 7(a). The porosity is completely absent due to the entrapment of DBT molecules in the micro and mesopores. However, after the spent adsorbent regeneration with toluene washing, the porous structure was once again achieved because of the DBT

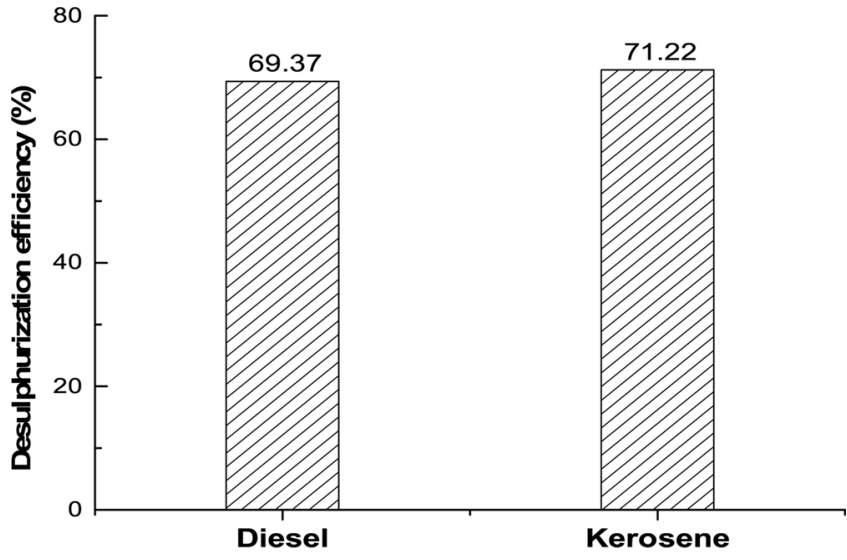

Fig. 8. Desulphurization efficiency of commercial oil samples by HCl-AC.

desorption from the blind pores and its solubility in toluene as depicted in Fig. 7(b) $[18,29]$.

\subsection{Desulphurization of real commercial oil samples}

The main objective of the current study was to modify the activated charcoal in such a manner that can selectively adsorb the aromatic sulfur species such as DBT from the model and commercial kerosene and diesel oil samples. Maximum DBT adsorption usually depends on both the surface chemical properties, such as the presence of active sites (surface functional groups) and their density, and also physical properties such as surface area, pore size, and distribution [22].

For the desulphurization of the real fuels, a set of previously optimized adsorption conditions were applied using model oil. Acid-modified AC showed a sharp increase in the desulphurization of the real oils as compared to the plain unmodified AC, where $69.37 \%$ and $71.22 \%$ of the total sulfur was removed from the diesel and kerosene oil samples respectively (Fig. 8). In comparison, the DBT adsorption from the model oil was much more significant than in the case of the real oils desulphurization. The same phenomenon was also observed by Olajire et al. [32]. It may be attributed to the complexity of the medium of the real fuels and also due to the competing bulky aromatic sulfur species present in the real fuels [33]. The active sites on the adsorbent surface are rapidly occupied and are blocked by the lighter sulfur species (BTs, DBTs, and MDBTs) and a drastic reduction in the active sites for the forthcoming bulkier sulfur species can be observed [34].

Jung et al. [15] used nitric acid modified activated carbon $\left(\mathrm{HNO}_{3}\right.$ AC) for the removal of benzothiophene (BT) from the model fuel. The results confirmed that the acid treatment of the AC has a profound effect on the selective adsorption of sulfur species. They also used hydrochloric acid modified activated carbon (HCl-AC), which showed quite similar performances to those of $\mathrm{HNO}_{3}-\mathrm{AC}$, confirming the advantageous effect of acid treatment.

Fig. 9(a,b) illustrates the SEM micrographs of the spent adsorbents

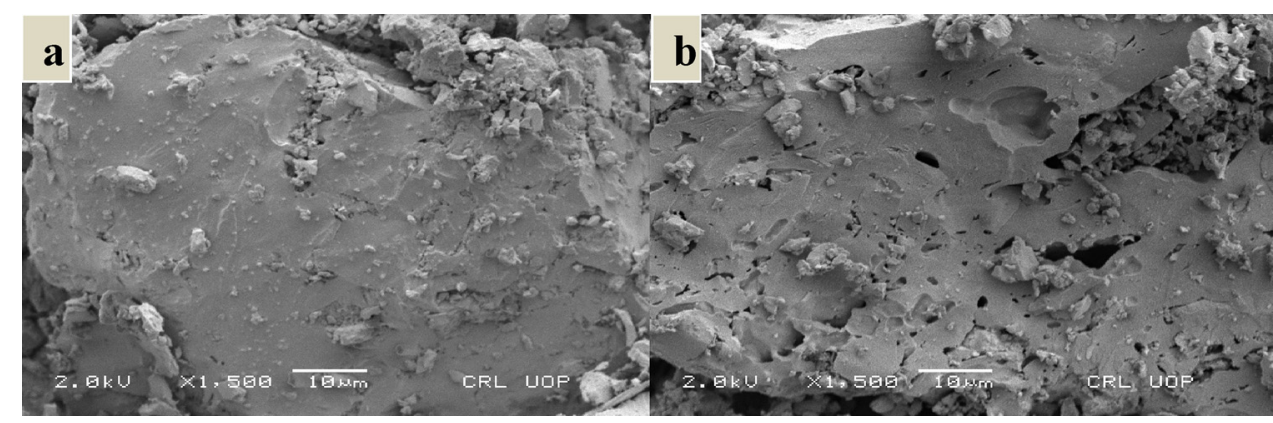

Fig. 7. SEM micrographs of $\mathrm{HCl}-\mathrm{AC}$ (a) before regeneration (b) after regeneration. 


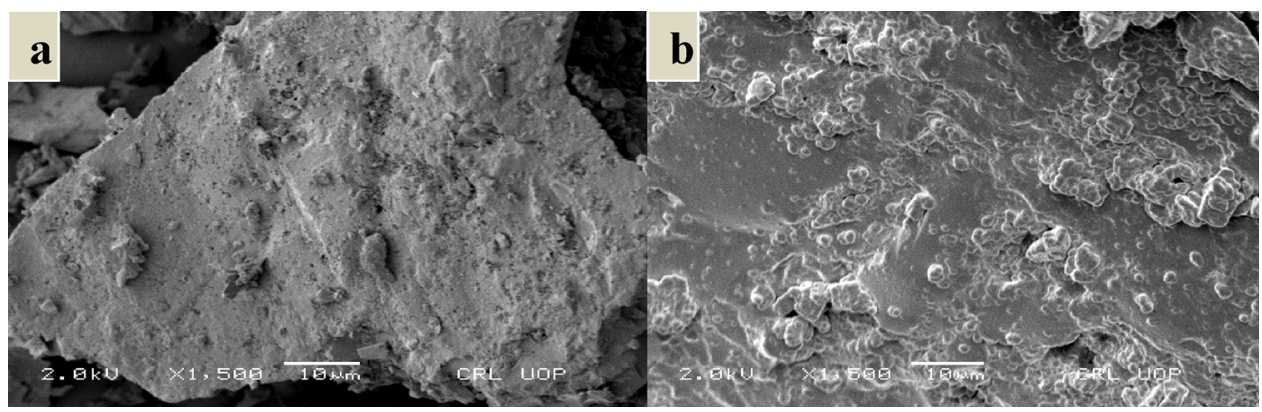

Fig. 9. SEM micrographs of spent adsorbents after the desulphurization of (a) kerosene and (b) diesel oil samples.

after the desulphurization of commercial kerosene and diesel oil samples. It is clearly evident that the porous nature of the adsorbent was diminished completely due to the real oil treatment. Moreover, due to the viscous nature of the diesel oil, some condensed masses appeared on the adsorbent surface. Diesel oil contains bulkier aromatic sulfur species that can act as the bottleneck on the adsorbent surface [34].

\section{Conclusions}

Activated Charcoal (AC) was modified with concentrated hydrochloric acid for the liquid-phase desulphurization of model and commercial fuel samples. Acid modification of AC showed an increased adsorption capacity due to the enhancement in its porosity and appearance of several different oxygen functional groups. Optimum adsorption parameters were adsorbent dosage $0.8 \mathrm{~g}$, contact time $60 \mathrm{~min}$, reaction temperature $25^{\circ} \mathrm{C}$, stirring speed $100 \mathrm{rpm}$, neutral $\mathrm{pH}$, and $1000 \mathrm{ppm}$ initial DBT concentration. The results from the current study showed that the DBT adsorption follows pseudo second-order kinetics and the current data best fitted to both the adsorption isotherm models. Toluene demonstrated to be the best washing solvent for the spent adsorbent regeneration. Compared to the other traditional adsorbents, $\mathrm{HCl}-\mathrm{AC}$ can have two advantages for the selective desulfurization application, with high adsorption capacity and the multifold regeneration ability. Results from the present study demonstrated that the acidmodified AC is a cost-effective and completely regenerable adsorbent for many folds and can be efficiently used in combination with other commercial desulphurization techniques for the selective desulphurization of refractory aromatic sulfur species from the commercial fuels.

\section{References}

[1] C. Song, An overview of new approaches to deep desulfurization for ultra-clean gasoline, diesel fuel and jet fuel, Catal. Today 86 (2003) 211-263, http://dx.doi. org/10.1016/S0920-5861(03)00412-7.

[2] T. Mochizuki, H. Itou, M. Toba, Y. Miki, Y. Yoshimura, Effects of acidic properties on the catalytic performance of CoMo sulfide catalysts in selective hydrodesulfurization of gasoline fractions, Energy Fuels 22 (2008) 1456-1462, http://dx. doi.org/10.1021/ef700644e.

[3] J. Rui, F. Liu, R. Wang, Y. Lu, X. Yang, Adsorptive desulfurization of model gasoline by using different Zn sources exchanged NaY zeolites, Molecules 22 (2017) 305, http://dx.doi.org/10.3390/molecules22020305.

[4] J. Bu, G. Loh, C.G. Gwie, S. Dewiyanti, M. Tasrif, A. Borgna, Desulfurization of diesel fuels by selective adsorption on activated carbons: competitive adsorption of polycyclic aromatic sulfur heterocycles and polycyclic aromatic hydrocarbons, Chem. Eng. J. 166 (2011) 207-217, http://dx.doi.org/10.1016/j.cej.2010.10.063.

[5] V. Chandra Srivastava, An evaluation of desulfurization technologies for sulfur removal from liquid fuels, RSC Adv. 2 (2012) 759-783, http://dx.doi.org/10.1039/ C1RA00309G.

[6] B. Pawelec, R.M. Navarro, J.M. Campos-Martin, J.L.G. Fierro, Retracted article: towards near zero-sulfur liquid fuels: a perspective review, Catal. Sci. Technol. 1 (2011) 23, http://dx.doi.org/10.1039/c0cy00049c.

[7] J.M. Campos-Martin, M.C. Capel-Sanchez, P. Perez-Presas, J.L.G. Fierro, Oxidative processes of desulfurization of liquid fuels, J. Chem. Technol. Biotechnol. 85 (2010) 879-890, http://dx.doi.org/10.1002/jctb.2371.

[8] F. Richard, T. Boita, M. Moreau, C. Bachmann, G. Pérot, Transformation of thiophenic compounds over HY zeolite: study of the acid-catalyzed isomerization and disproportionation mechanisms by quantum chemical calculations, J. Mol. Catal. A Chem. 273 (2007) 48-54, http://dx.doi.org/10.1016/j.molcata.2007.03.061.
[9] P.M. Paniv, S.V. Pysh'ev, V.I. Gaivanovich, O.I. Lazorko, Noncatalytic oxidation desulfurization of the kerosene cut, Chem. Technol. Fuels Oils 42 (2006) 159-166, http://dx.doi.org/10.1007/s10553-006-0049-4.

[10] S. Kumagai, Y. Shimizu, Y. Toida, Y. Enda, Removal of dibenzothiophenes in kerosene by adsorption on rice husk activated carbon, Fuel 88 (2009) 1975-1982, http://dx.doi.org/10.1016/j.fuel.2009.03.016.

[11] S. Kumagai, H. Ishizawa, Y. Toida, Influence of solvent type on dibenzothiophene adsorption onto activated carbon fiber and granular coconut-shell activated carbon, Fuel 89 (2010) 365-371, http://dx.doi.org/10.1016/j.fuel.2009.08.013.

[12] R. Mailler, J. Gasperi, Y. Coquet, C. Derome, A. Buleté, E. Vulliet, et al., Removal of emerging micropollutants from wastewater by activated carbon adsorption: experimental study of different activated carbons and factors influencing the adsorption of micropollutants in wastewater, J. Environ. Chem. Eng. 4 (2016) 1102-1109, http://dx.doi.org/10.1016/j.jece.2016.01.018.

[13] E. Asuquo, A. Martin, P. Nzerem, F. Siperstein, X. Fan, Adsorption of Cd(II) and Pb (II) ions from aqueous solutions using mesoporous activated carbon adsorbent: equilibrium, kinetics and characterisation studies, J. Environ. Chem. Eng. 5 (2017) 679-698, http://dx.doi.org/10.1016/j.jece.2016.12.043.

[14] J. Qiu, G. Wang, Y. Bao, D. Zeng, Y. Chen, Effect of oxidative modification of coal tar pitch-based mesoporous activated carbon on the adsorption of benzothiophene and dibenzothiophene, Fuel Process Technol. 129 (2015) 85-90, http://dx.doi.org/ 10.1016/j.fuproc.2014.08.022.

[15] B.K. Jung, S.H. Jhung, Adsorptive removal of benzothiophene from model fuel, using modified activated carbons, in presence of diethylether, Fuel 145 (2015) 249-255, http://dx.doi.org/10.1016/j.fuel.2014.12.088.

[16] X. Han, H. Lin, Y. Zheng, Adsorptive denitrogenation and desulfurization of diesel using activated carbons oxidized by (NH4)2S2O8 under mild conditions, Can. J. Chem. Eng. 93 (2015) 538-548, http://dx.doi.org/10.1002/cjce.22132.

[17] S.S. Shah, I. Ahmad, W. Ahmad, Adsorptive desulphurization study of liquid fuels using Tin (Sn) impregnated activated charcoal, J. Hazard. Mater. 304 (2016) 205-213, http://dx.doi.org/10.1016/j.jhazmat.2015.10.046.

[18] A. Zhou, X. Ma, C. Song, Liquid-phase adsorption of multi-ring thiophenic sulfur compounds on carbon materials with different surface properties, J. Phys. Chem. B 110 (2006) 4699-4707, http://dx.doi.org/10.1021/jp0550210.

[19] S.S. Shah, I. Ahmad, W. Ahmad, M. Ishaq, H. Khan, Deep desulphurization study of liquid fuels using acid treated activated charcoal as adsorbent, Energy Fuels 31 (2017) 7867-7873, http://dx.doi.org/10.1021/acs.energyfuels.7b00914.

[20] G.M. Bansal, R.C. Bansal, M. Goyal, Activated Carbon Adsorption, CRC Press Inc., Boca Raton, FL, 2005.

[21] M.F. de. Aguiar, G.L.V. Coelho, Adsorption of sulfur compounds from natural gas by different adsorbents and desorption using supercritical CO 2, J. Environ. Chem. Eng. 5 (2017) 4353-4364, http://dx.doi.org/10.1016/j.jece.2017.07.079.

[22] J.H. Kim, X. Ma, A. Zhou, C. Song, Ultra-deep desulfurization and denitrogenation of diesel fuel by selective adsorption over three different adsorbents: a study on adsorptive selectivity and mechanism, Catal. Today 111 (2006) 74-83, http://dx. doi.org/10.1016/j.cattod.2005.10.017.

[23] Z. Jiang, Y. Liu, X. Sun, F. Tian, F. Sun, C. Liang, et al., Activated carbons chemically modified by concentrated H 2 SO 4 for the adsorption of the pollutants from wastewater and the dibenzothiophene from fuel oils, Langmuir 19 (2003) 731-736, http://dx.doi.org/10.1021/la020670d.

[24] A. Bandyopadhyay, M. Biswas, Removal of hexavalent chromium by synergism modified adsorption, Indian J. Environ. Prot. 18 (1998) 662-671.

[25] L. Nouri, I. Ghodbane, O. Hamdaoui, M. Chiha, Batch sorption dynamics and equilibrium for the removal of cadmium ions from aqueous phase using wheat bran, J. Hazard. Mater. 149 (2007) 115-125, http://dx.doi.org/10.1016/j.jhazmat.2007. 03.055.

[26] D. Richardeau, G. Joly, C. Canaff, P. Magnoux, M. Guisnet, M. Thomas, et al., Adsorption and reaction over HFAU zeolites of thiophene in liquid hydrocarbon solutions, Appl. Catal. A Gen. 263 (2004) 49-61, http://dx.doi.org/10.1016/j. apcata.2003.11.039.

[27] H. Song, Y. Chang, X. Wan, M. Dai, H. Song, Z. Jin, Equilibrium, kinetic, and thermodynamic studies on adsorptive desulfurization onto CuICeIV Y zeolite, Ind. Eng. Chem. Res. 53 (2014) 5701-5708, http://dx.doi.org/10.1021/ie403177t.

[28] L. Abramian, H. El-Rassy, Adsorption kinetics and thermodynamics of azo-dye Orange II onto highly porous titania aerogel, Chem. Eng. J. 150 (2009) 403-410, http://dx.doi.org/10.1016/j.cej.2009.01.019.

[29] C.C. Schmitt, S.S.X. Chiaro, V.O. de Andrade Tanobe, E.V. Takeshita, C.I. Yamamoto, Regeneration of activated carbon from babassu coconut refuse, 
applied as a complementary treatment to conventional refinery hydrotreatment of diesel fuel, J. Clean. Prod. 140 (3) (2017) 1465-1469, http://dx.doi.org/10.1016/j. jclepro.2016.10.004.

[30] N. Farzin Nejad, E. Shams, M.K. Amini, J.C. Bennett, Synthesis of magnetic mesoporous carbon and its application for adsorption of dibenzothiophene, Fuel Process. Technol. 106 (2013) 376-384, http://dx.doi.org/10.1016/j.fuproc.2012.09.002.

[31] X. Ma, L. Sun, C. Song, Adsorptive desulfurization of diesel fuel over a metal sulfidebased adsorbent, Prepr. Pap. - Am. Chem. Soc., Div. Fuel Chem 48 (2003) 522-523 https://web.anl.gov/PCS/acsfuel/preprint archive/Files/48_2_New York_10-03_ 0597.pdf (Accessed 28 March 2017).
[32] A.A. Olajire, J.J. Abidemi, A. Lateef, N.U. Benson, Adsorptive desulphurization of model oil by Ag nanoparticles-modified activated carbon prepared from brewer's spent grains, J. Environ. Chem. Eng. 5 (2017) 147-159, http://dx.doi.org/10.1016/ j.jece.2016.11.033.

[33] M. Wang, S. Zhao, L. Ren, Y. Han, C. Xu, K.H. Chung, et al., Refractory cyclic sulfidic compounds in deeply hydrodesulfurized diesels, Energy Fuels (2017), http://dx.doi.org/10.1021/acs.energyfuels.7b00007 (acs.energyfuels.7b00007).

[34] O. van Rheinberg, K. Lucka, H. Köhne, T. Schade, J.T. Andersson, Selective removal of sulphur in liquid fuels for fuel cell applications, Fuel 87 (2008) 2988-2996, http://dx.doi.org/10.1016/j.fuel.2008.03.020. 